\title{
The Relationship of the Aflatoxin in the Diet on Rat Liver Tissue
}

\author{
D.O.I - 10.51201/Jusst12652 \\ http://doi.org/10.51201/Jusst12652 \\ Dr. Saba Thamer Mosa \\ Department of Internal and Preventive Veterinary Medicine, College of Veterinary Medicine, \\ Baghdad University, Baghdad, Iraq.
}

\begin{abstract}
Aflatoxins are produced by certain strains of fungi under warm, humid conditions during the growth of plants in the field and during storage of plant products (grains, legumes, nuts) and also they grow on some foodstuffs and animal feed. They are natural metabolism byproducts produced by molds and are considered one of the most dangerous compounds that cause carcinogenicity. If a person or animal consumes a food containing aflatoxin, they are vulnerable to many health problems.

It has been found that the most dangerous aflatoxin is aflatoxin B1 because it works on cellular membranes as it inhibits RNA synthesis and is considered one of the factors that cause mutations due to its effect on DNA and also has an effect on the liver and is considered one of the strongest carcinogen compounds, which leads to the occurrence of tumors in the liver in case It is present in food at concentrations of $10 \mathrm{ppb}$. It was also found to have an immunosupressive effect on the body's immune system.
\end{abstract}

\section{Introduction}

Mycotoxins, or Aflatoxins, are toxic carcinogens produced by some molds (Aspergillus flavus and Aspergillus parasiticus) that grow in soil, decaying vegetables, hay, and grains. It is naturally found in improperly stored staple foods, such as cassava, chili peppers, corn, cottonseeds, millet, peanuts, rice, sesame seeds, sorghum, sunflower seeds, nuts, wheat, and a variety of spices. When contaminated food is processed, mycotoxins enter the general food supply where they are found in human and pet foods, such as raw materials provided to farm animals. In turn, animals that feed on contaminated food transfer mycotoxins to eggs, dairy products, and meat. [1]

Mycotoxins are considered one of the most dangerous toxins to human and animal health, the most famous of which are four: aflatoxin, alfumonsin, ziralonin, and fumitoxin, but aflatoxin is the most famous and most dangerous of all, it is found in a large number of foods, and it is sufficient for a person to be exposed to a small amount of it, not exceeding Parts per million, to kill it. The World Health Organization indicated that aflatoxin poisoning can cause death, and if children are exposed to it for a long time, major complications may occur to them, most notably stunting, weight loss, and damage to the immune system. Aflatoxin toxins enter the human body either directly through food, or indirectly by eating products originating from animals that have previously fed on feed contaminated with mycotoxins, which are most dangerous.[1,2] 
Aflatoxin toxins are produced from a fungus called Aspergillus flavus, which grows and thrives on many foods, most notably peanuts, nuts (pistachios, walnuts, cashews and almonds), corn, wheat, rice, barley, oil seeds, legumes, contaminated fruits, dates, thyme, and coffee. [2] Aflatoxins are commonly taken with food. However, the most toxic form of aflatoxin, B1, can permeate through the epidermis. FDA-determined action levels for aflatoxins in food or feed are 20 to $300 \mathrm{ppb}$. The FDA has previously announced orders to withdraw food for humans and animals as a precaution to prevent exposure to aflatoxin.

The name aflatoxin derives from the name of one of the mold species it produces, Aspergillus flavus. This was formulated around the year 1960 after it was discovered as a causative agent of "Turkey X disease." [3] Mycotoxin (Aflatoxin) is one of the main concentrations of mycotoxin:

\section{Clinical symptoms seen in rabbits infected with aflatoxin poisoning:}

New Zealand white rabbits fed on diets contaminated with aflatoxin showed satisfactory symptoms, including loss of appetite, which increases with the period of exposure to contaminated food, animals fed with food contaminated with a high concentration of aflatoxin B1 (100 ppb) had a higher rate of water consumption than comparable rabbits Rabbits before death were suffering from severe weakness, sluggishness in movement, black and sometimes bloody diarrhea, emaciation, severe high temperature (fever), and it has been observed that the decrease in weight may reach $30 \%$ of the live weight, some cases of rabbits that She was fed polluted diets that showed irritation in the nervous system, some suffered from severe swelling in the abdominal area, and some had paralysis in the hind limbs.As for the dissection of dead rabbits, signs appeared that were seen with the naked eye.[4-6]

\section{Growth Performance:}

The results showed that rabbits fed on diets containing different levels of aflatoxin B1 were found that their weights in the first and second week were not affected by the levels of aflatoxin B1, but there was a significant decrease (at 0.005 level) in weight at the third, fourth, fifth and sixth weeks compared to control 0 The low level of aflatoxin B1 (25 ppb) led to an increase in weight over the control at a significant level (0.05) from the third week to the sixth week.

\section{Adsorbed substances}

Body weight from the beginning of the experiment until the second week, but from the third week to the sixth week there was an increase in body weight when adding the clay, and the increase was higher than in the case of adding aluminum silicate.

Adding $0,5 \%$ of mud led to a significant increase at the level of $(0.00)$ in body weight from the third week to the sixth week.Adding $0,5 \%$ or $1 \%$ aluminum silicate improved body weight, but there was no significant difference between $0,5 \%$ and $1 \%$ aluminum silicate.[7]

\section{Increase in body weight:}

Feeding rabbits on diets contaminated with aflatoxin led to a decrease in the increase in body weight at the level of insulin (05.0) from the beginning of the experiment to the end of the experiment, while the concentration of $25 \mathrm{ppb}$ increased the final weight compared to the control of the adding the adsorbed materials (clay, silica) had no significant effect on the final 
weight, the increase in the body from the beginning of the experiment until the ninth week and from the sixth week until the ninth week, the addition of clay or aluminum silicate at a rate of zero led to the final weight gain and weight gain from the beginning of the experiment until the ninth week and from the sixth week until the ninth week.

The low level of aflatoxin ( $25 \mathrm{ppb}$ ) led to an increase in body weight, in contrast to the higher levels (50,100 ppb of aflatoxin), which caused a decrease in body weight at a significant level (0.05). Adding $0.5 \%$ of the clay to the aflatoxin-polluted diets improved the weight gain at the sixth week. Adding clay is better than aluminum silicate, as it led to an increase in body weight.[8,9]

\section{Chemical analysis of rabbit meat:}

The chemical analysis of the rabbits' body at the sixth week of the experiment showed a gradual decrease (with a 0.05 significant level) in crude protein and a gradual increase (with a 0.005 significant level) in raw fat (etheric extract) 0 animals fed on a diet contaminated with aflatoxin at a level of $100 \mathrm{ppb}$. addition of agglutinants (clay - aluminum silicate) had no significant effect on the chemical analysis in the sixth week. Adding $0,5 \%$ clay or $1 \%$ aluminum silicate reduced crude fat and increased protein and ash in the carcass.[10]

The rabbits age (in the ninth week), it was noticed that the level of aflatoxin and the adsorbed material (clay - aluminum silicate) did not significantly affect the chemical analysis. Adding $1 \%$ clay or $1 \%$ silica reduced the fat and increased both protein and ash.The toxin residues at the sixth week were high in the liver, followed by muscle, then heart, then kidney,adding the slurry reduced the toxin residues in the sixth week than adding the aluminum silicate (at 0.005 significance level) adding 0,5\% clay to contaminated feed was sufficient to reduce toxin residues in the sixth week in the internal organs of the rabbit's body. However, there was no significant difference between the concentration of $0,05 \%$ clay, $1 \%$ clay, as well as $0,5 \%$ silica, $1 \%$ silica.[11]

It was found in the ninth week that the low level of toxin $(25 \mathrm{ppb})$ led to an increase of residual in the liver and the increase was significant (at 0.005 significance level) Levels 25 and $50 \mathrm{ppb}$ aflatoxin increased in their animals toxin residues in the heart, kidneys and muscles compared to the control in the ninth week.[12]

\section{Blood measures:}

Feeding New Zealand rabbits on diets contaminated with aflatoxin at different concentrations in the sixth week resulted in:Minerals (calcium, phosphorous) were not affected by aflatoxin 0 concentrationsa decrease in hemoglobin level, the volume ratio of blood particles (hematocrit) a significant decrease (at 0.005 level of significance) for glucose and cholesterol An increase in the activity of liver enzymes to transport amine groups (GOT, GPT) and an increase in the concentration of uric acid, urea and creatinine.The adsorption material did not affect blood minerals and all other measurements were studied Adding 0,5\% clay or $1 \%$ aluminum silicate reduced significantly (at 0.005 level) the activity of enzymes (GOT, GPT), [12] 


\section{Histological investigation:}

The most important pathological changes were observed in the liver, kidneys, heart and lungs. Changes in the liver included exudation, congestion and hemorrhage, as well as bifurcation and infiltration in the connective tissues and cells surrounding the bile duct, congestion of blood vessels in the portal region, and the occurrence of dispersion in hepatocytes, with the replacement of hepatocellular brachima with single cells.[13]

As for the kidneys, congestion appeared in the renal blood vessels, with chronic inflammation of the renal tubules, with infiltration of mononuclear cells 0 . As for the lung, it had a swelling in the pulmonary vessels, an increase in the mononuclear cells, congestion beside the dissolution of the vesicles, an increase of chromatin with smoothness of the trachea, and replacement Cells are mononuclear cells. From the aforementioned, it becomes clear how dangerous aflatoxin food contamination is to animals (and the human being who consumes meat products of these animals contaminated with nutrition) and that the adsorbed material (even if it limits the absorption of toxins)

The fungi of the feed and its components in order to thus prevent the production of toxin on the feed, meaning that prevention remains better than treatment.[14]

\section{References:}

1. Knoess, K.H., (1979). Milk production of the dromedary. Proceeding of the IFS Symposium Camels, Sudan, pp: 201-214.

2. Konuspayeva, G., B. Faye and G. Loiseau. (2009). The composition of camel milk: a meta-analysis of the literature data. J. Food Compos. Anal. 22: 95-101.

3. Haddadin, M. S. Y., S. I. Gammoh and R. K. Robinson. (2008). Seasonal variations in the chemical composition of camel milk in Jordan. J. Dairy Res. 75: 8-12.

4. Rao, M.B., R.C. Gupta and N.N. Dastur, (1970). Camels' milk and milk products. Ind. J. Dairy Sci.78-71:23,

5. El-Agamy, E. I. and M. Nawar. (2000). Nutritive and immunological values of camel milk: Acomparative study with milk of other species. In: Proc. 2nd International CamelidConference: Agroecons. Camelid Farm, Almaty, Kazakhstan. 8-12 Sept.

6. El-Agamy, S.I., R. Ruppanner, A. Ismail, C.P. Champagne and R.J. Assaf, (1992). Antibacterialand Antiviral activity of camel milk protective proteins. J. Dairy Res., 59: 169-175.

7. Althnaian, T. (2012). Protective effect of camel milk against carbon tetrachloride hepatotoxicity inrats. Global Veterinaria 9 (5): 564-570.

8. Bancroft, J.D. and Stevens, A. 1987. Theory and practice of histological techniques. Edinburgh:Churchill Livingston. Pp: 482-502.

9. Beth, D.; Robert, G. and Trapp. (2004). Basic and clinical biostatistics, 4th ed. Lange MedicalBooks/ Mc Graw-Hill Medical Publishing Division. New York. PP: 83-154.

10. Aoki, M., and Y. Tani. (1972). Growth and histopathologic changes in mice fed with hydrogenperoxide solution instead of water. Igaku To Seibutsugaku 84: 159- 162.

11. Khudiar, K. K. (2010). Effect of $1 \%$ hydrogen peroxide (H2O2) in drinking water on someparameters in , adult male rabbits. Iraqi J. Biotech. 9(2):202-210.

12. Rahim, S. M., Ekhlass M. T., Muneef S., Bushra I., Kumar D. and Abd Gaffar M. (2014).Hepatoprotective effect of cymbopogon citratus aqueous extract against 
hydrogen peroxideinduced liver injury in male rats. J Tradit Compl. Altern Med. 11(2):447-451.

13. Althnaian, T., Ibrahim A. and Sabry M E. (2013). Biochemical and histopathological study in ratsintoxicated with carbontetrachloride and treated with camel milk. J. SpringerPlus. 2(57):1-7.

14. Darwish, H. A., Naglaa R. A. and Amina M. (2012). Camel's milk alleviates alcohol-induced liverinjury in rats. J. Food and Chem. Toxico. $50: 1377-1383$. 